\section{Community engagement in the introduction and implementation of the National Health Insurance in South Africa}

\author{
Geoffrey Setswe, Jackie Witthuhn \\ Monash South Africa School of Health \\ Sciences, Roodepoort, South Africa
}

\section{Abstract}

The South African government released a policy document for the introduction of a National Health Insurance (NHI) system planned to start in 2012. The consultation process for involving the public in the implementation of the NHI was also announced in August. When the consultation process on the NHI was announced, everyone assumed that the Government's aim was to devolve power to communities and create a more patientfocused and community-oriented NHI. In this paper we look not only at how community engagement process on the NHI works, but we also review the democratic process to determine if it is a good means of holding decision makers to account to communities before and during the implementation of the NHI in South Africa. We review reasons for involving or engaging communities in health and related matters, the policy context of community engagement and review potential roles of nongovernmental organizations in assisting people to participate in debates for implementation of this new health policy initiative.

\section{Introduction}

The objectives of the paper are to describe the process of Community engagement in the introduction and implementation of the National Health Insurance (NHI) in South Africa. Community engagement is defined as the process whereby public bodies reach out to communities to create empowerment opportunities' and community empowerment as 'the giving of confidence, skills, and power to communities to shape and influence what public bodies do for, or with them (p 12). ${ }^{1}$

According to Gregory et al., ${ }^{2}$ community engagement also refers to the process of involvement of the community in the planning of policies and services. In a health policy context, it is about involving community members in developing and implementing the policies that will affect them as health consumers. It includes decisions about the delivery of health budgets, and broader systematic questions about the type of health systems that people want to have.

In recent years, there has been a recognition that the public service in South Africa needs to be more directly accountable to the people who both pay for and use them. It is not enough for accountability to happen upwards through the Government to Parliament and the people. Accountability must also have a local component, so that decision makers are answerable to the very communities affected by their decisions. One way to make decision making more locally accountable is to make it more open and transparent, for example through scrutiny by elected representatives. Another is to engage local communities in the decision making process itself.

As citizens in a democracy, we want decision makers to answer to us for the quality of our public services. As patients and users of services, we want decision makers to listen to us, understand our experiences of services and shape them accordingly. As members of the communities we live in, we want that dialogue to have a local dimension. ${ }^{3}$

These powerful arguments - which have parallels across all public service in South Africa - underpin policy and legislative changes that were announced in August 2011 designed to enable the full participation of communities and their elected representatives in both the commissioning and the delivery of the new National Health Insurance in South Africa.

Community engagement is built on the principles of equality and social justice. It acknowledges that barriers to public health and social care services exist for many people and that those barriers are often rooted in the failure of agencies to adequately recognize the complex social, cultural, religious, economic and generational experiences of distinct communities. ${ }^{4}$

When the consultation process on the NHI was announced in August, we assumed that the Government's aim was to devolve power to communities and create a more patientfocused and community-oriented NHI.

The limitation of this review is that the process of community engagement had not been completed when the manuscript was submitted so we don't have the benefit of hindsight.

\section{Methods of research}

A literature search was conducted to gain perspective on how community engagement process on the NHI works, but we also reviewed the democratic process to determine if it is a good means of holding decision makers to account to communities before and dur-
Correspondence: Geoffrey Setswe, School of Health Sciences, Monash South Africa, 144 Peter Road, Private Bag X60, Ruimsig, Roodepoort 1725 , South Africa.

Tel. +27.11.950.4329.

E-mail: geoffrey.setswe@monash.edu

Key words: community, engagement, implementation, health, insurance.

Funding: we wish to thank the 0xfam-Monash Committee for funding the National Health Insurance accountability project in South Africa.

Contributions: GS, main author, manuscript first draft; JW, co-author, manuscript writing ( $30 \%$ of the content).

Conflict of interests: the authors declare no potential conflict of interests.

Received for publication: 12 December 2011. Revision received: 29 April 2013.

Accepted for publication: 26 May 2013.

This work is licensed under a Creative Commons Attribution NonCommercial 3.0 License (CC BYNC 3.0).

(C) Copyright G. Setswe and J. Witthuhn, 2013 Licensee PAGEPress, Italy

Journal of Public Health in Africa 2013; 4:e6 doi:10.4081/jphia.2013.e6

ing the implementation of the NHI in South Africa. The search aimed to locate a range of articles referring to implementation of the $\mathrm{NHI}$ as well as in the grey literature (government and non-government organization reports). A combination of community engagement, community participation and National Health Insurance, Social Health Insurance were used as search terms in the Medline database, while a combination of engagement and policy were used as search terms in the EconLIT and Business Source Premier databases. The authors were referred to other scientific literature and relevant grey literature by their contacts in the fields of health policy and public health law.

In reviewing the community engagement approaches from the literature, we confined our analysis to countries where the National Health Insurance policies were introduced. Our scope included implementation of $\mathrm{NHI}$ policies within government agencies, non-governmental organizations and the private sector because these were considered to complement the policy interventions at a government level.

We were compelled to use a literature review for this paper, as there is no existing data and research on participation in the NHI in South Africa. It is a new initiative that has only started in the past few months. The limitation of this method is that you depend on 
research and reports provided by researchers from other countries where participation in the health vibrant, or researchers depend on research from fields other than health where communities participated in development activities. We dealt with this limitation by carefully selecting research and case studies that closely resemble participation and/or health, particularly health insurance, where possible.

\section{Findings and discussion}

\section{Reasons for involving or engaging communities in health and related matters}

There are several compelling reasons for involving or engaging communities in the planning and implementation of health promotion and health services, including the introduction of a significant project such as the National Health Insurance.

Kahssay and Oakley ${ }^{5}$ outlined the five key benefits of community involvement: i) coverage and the involvement of more people; ii) efficiency and the better coordination of resources; iii) effectiveness as a result of more relevant goals and strategy; iv) equity through focused provision for those in greatest need; v) the growth of self-reliance and local capacity.

To achieve these benefits, there are many ways that communities can be engaged in health improvement. These can range from large-scale public, formal consultations, with the involvement of democratically elected representatives, to intensive ongoing involvement of small groups of patients in developing services around a common medical condition, to empowering and appropriately remunerating members of small neighborhood communities to act as advocates, health trainers or community development workers. ${ }^{3}$

Coulter ${ }^{6}$ reflects on four reasons why community engagement in health is worthwhile: i) to determine local needs and aspirations; ii) to promote health and to reduce inequalities; iii) to improve service design and quality care; and iv) to strengthen local accountability.

Gregory et $a .^{2}$ also agree that community engagement can operate at a variety of levels, ranging from simple information gathering exercises that involve listening to the community's perspectives, through to more complex processes that are built around two-way conversations, deliberations, and collaborative decision making. The continuum of engagement developed by Health Canada provides a useful tool for defining engagement levels. Their five-level continuum describes a spectrum from low level to high-level public involvement and provides examples of when each level might be useful. The five levels defined by Health Canada are: i) inform/educate; ii) gather information; iii) discuss; iv) engage; v) partner.

Deliberative approaches to community engagement typically provide a high level of public involvement and would be positioned at level 4 (engage) or level 5 (partner) of the Health Canada continuum. In contrast, the more traditional approaches to engagement such as invitations for community submissions, surveys to gather information, public meetings or inviting individual consumers to work on committees as consumer representatives, are clustered around the middle level of the Health Canada continuum.

The advantages of joint engagement strategies include: i) increased capacity to engage people at the interface between health and other services, such as social services (an area in which services have been less than seamless in the past); ii) opportunities to use and build on existing networks and methodologies previously tested within the different sectors; iii) a way of bringing together commissioners and providers across services to listen and respond collectively to service users and the public - an opportunity for people to get out of their silos; iv) the avoidance of duplication of effort, which as well as being a waste of resources can cause consultation fatigue; v) reducing the chances of failing to engage with all relevant parts of the community. ${ }^{3}$

The Local Government Association Health Commission report called who's accountable for health? ${ }^{7}$ contained a list of recommendations to strengthen the accountability links between the NHS and local government. The Commission looked at community engagement in the wider context of democratic accountability. In addition they had recommendations about ensuring that patients and the public are better informed about how they can access the health system and make their voices heard. To confirm this, here is a quote on the importance of accountability:

I want to argue that there is a perfectly acceptable role in public life and that it is the job of holding powerful people to account. ${ }^{8}$

In the UK, the Centre for Public Scrutiny (CfPS) was set up to support anyone with a non-executive role in the public sector. One of the CfPS principles of good scrutiny is that it enables the voice and concerns of the public to be heard. ${ }^{9}$ In South Africa, we do not have strong accountability structures that will ensure that the voices of the poor and marginalized are heard on the implementation of the National Health Insurance. Here is a quote confirming the importance of involving people in making decisions:

When people are involved in making the decisions, which affect their lives their selfesteem and self-confidence raise, in turn improving their health and wellbeing. And, of course, many local people have a good understanding of the community's main health problems and of priorities for action. Real change can come only from the local community itself by harnessing the energy, skills and commitment of local people in setting clear objectives for change and forming new partnerships for action. $^{10}$

The model in Figure 1 describes pathways from community participation, empowerment and control to health improvement in a community. ${ }^{11}$ It proposes that increasing community participation in a project such as the National Health Insurance requires that there should be community control, delegated power, co-production, consultation and informing. Service outcomes that can be expected out of this model include more appropriate and accessible service and improved uptake of the NHI. Intermediate and social outcomes include impact on social capital and enhanced community empowerment, improved social and material conditions while health outcomes that can be expected from implementing this model include improved health status and reduced health inequalities.

\section{The policy context of community engagement in health}

Since the advent of democracy in South Africa, government policy has promoted the involvement of people from communities in the development and delivery of improvement programs. Examples have included the Child Care Act, Abortion Act, Gun laws and now the National Health Insurance policy. With regards to the Termination of Pregnancy Act (1997), Harrison et al. ${ }^{12}$ noted that legislation alone cannot ensure implementation of abortion services. Harrison et al. highlighted the importance of media coverage, public education, community consultation and information sharing prior to implementation of legislation. The Government has attempted to link national strategies with local design and implementation by putting community engagement at the heart of such initiatives. Community engagement is becoming an embedded feature of government policy.

Engaging and empowering communities are linked to community cohesion. Initiatives to engage people in improving health and reducing health inequalities are one way of showing a commitment to and building community cohesion, as well as being good in them.

Community, of course, is a contested concept, particularly in an unequal society such as South Africa. The term has been used to suggest a romanticized and idealized world of mutual support from family, friends and neighbors, free from political conflicts and debate. ${ }^{2}$ Rich neighborhoods such as Randburg (in the 
northern suburbs of Johannesburg) are compared with most deprived neighborhoods such as Zandspruit informal settlement in the way they respond to the NHI. Rich neighborhoods can use various community engagement approaches to make their input into the NHI. These include community meeting, petitioning the local councilor, minister or even Parliament, writing letters in local and national newspapers, and using technology such as emails and social networking mechanisms such as Face book, twitter or developing a blog to state their opinions on the NHI.

However, when deprived rural and squatter neighborhoods are compared with this vision, they are found wanting. They lack the resources, coordination and cohesion capabilities that their better-off neighbors have. They are said to have lost the magical ingredients that make up real communities, a loss that might be revealed when there are no or poor submissions from these communities on the $\mathrm{NHI}$ at the end of the three months consultation process.

The Black Sash and the Oxfam-Monash teams are some of only a few organizations that are working with rural and peri-urban communities to inform them about the NHI and obtain their views on its implementation, particularly in their own communities.

In fact, the real problem is as likely to be that wider economic and social circumstances have put extra stress onto the deprived rural and squatter communities; and our public services have struggled to deal with this. Often the people living in these communities have shown real strengths in providing mutual support and helping each other out. They need access to the same good quality services that we all expect, an adequate income and employment. These are some of the basic determinants of good health.

The picture is further complicated in deprived communities as networks have grown up in response to the perceived or actual needs of these communities. They form part of the cash or underground economy that comprises societies, social clubs, stokvels, burial societies and loan schemes. Networks can sometimes have a negative impact as they may function to exclude individuals, groups or agencies. In areas where the underground economy's link to crime is strong they can be controlling. When working with communities it is important to ensure local community leaders are working in the best interests of local people and not taking a partial or biased approach, which could be in opposition to attempts at community engagement from outsiders. $^{3}$

The role of politicians in ensuring that the views of the communities are heard is murky. Our ideal expectation is that the community voice, combined with politicians' mandate to

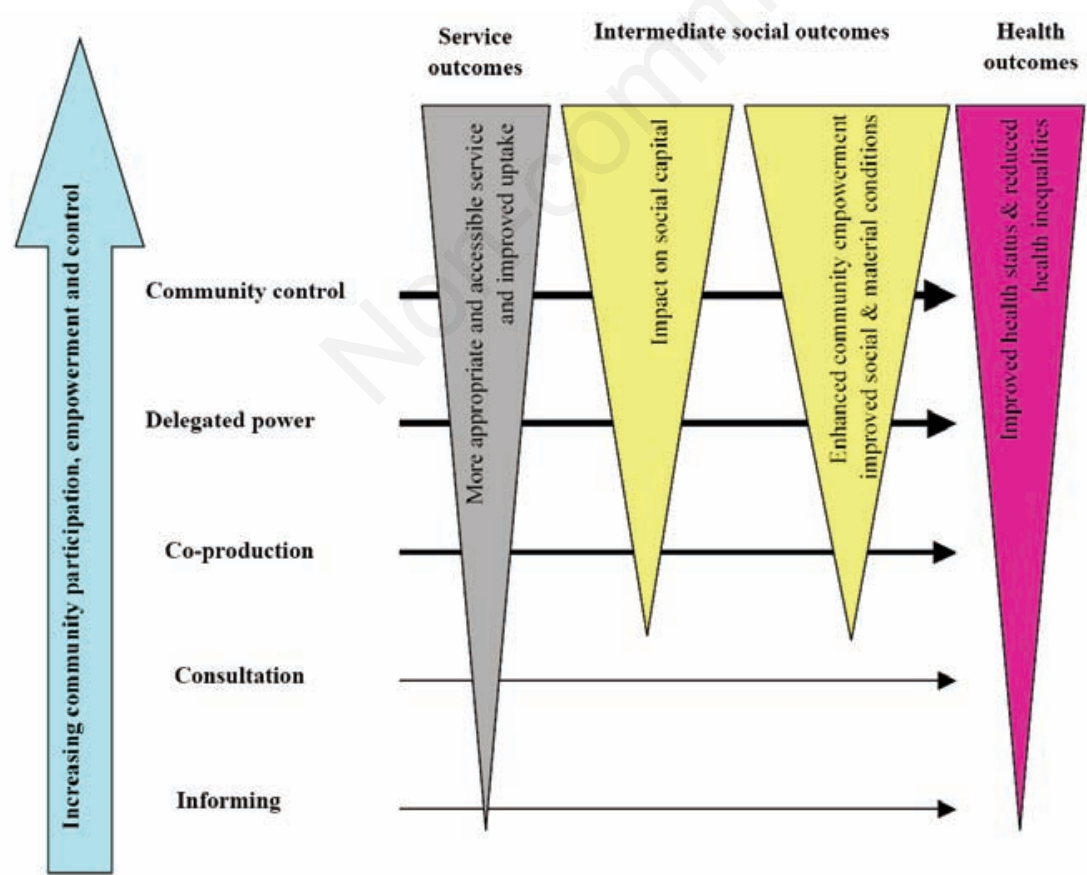

This diagram is reproduced from Popay J (2010) Community Engagement for Health Improvement: questions of definition, outcomes and evaluation, in Morgan A.. Barker R.. Davies M.. Ziglio, E. (Eds). Health Assets in a Global Context: Theory, Methods. Action. New York: Springer. pp. 183-197.

Figure 1. Pathways from community participation, empowerment and control to health improvement (modified from Popay, 2010, with permission). ${ }^{11}$ act with and on behalf of the public, can be a powerful lever for change. The framework for locally accountable health and care sometimes appears incoherent - politicians as guardians and shapers of the local area have a real role to join up the various mechanisms that exist, putting the empowering of communities at the heart of everything they do.

\section{The role of non-governmental \\ organizations}

Non-governmental organizations (NGOs) often have a holistic view of the activities undertaken by public sector organizations in an area. In ensuring that the Department of Health engages effectively with residents and communities on the NHI, NGO partners can bring a different perspective, expertise and knowledge to discussions. The civil society sector can play a key role in helping to identify and set priorities, and in monitoring the performance of public health services, with greater use of peer-led and citizen review. Nongovernmental organizations can provide a strong community empowerment and community development ethos along with infrastructure and encourage discussion and debate about the big strategic issues, as well as important local issues, so as to increase understanding of the NHI.

Involving NGOs is not and should not be seen as a proxy for engaging local communities and service users themselves, although many organizations do provide a useful gateway to the community. However, the civil society sector can promote public engagement in the NHI in a number of ways. Ensuring that their users and members have access to good quality health and social care is a concern for many voluntary and community organizations, not just those with a specific health mission. This means that there is usually a core of significant interest in and activity on these issues locally.

Besides having direct knowledge of local needs and preferences, and experience of engaging with local people, NGOs also provide a channel of communication to local communities. As such they can enable a diversity of views to be expressed and give voice to a range of different interests and concerns. Most crucially they can provide a link to those who would otherwise find it difficult to participate or make their views heard. Local organizations often have infrastructure such as a building in the community and can be a good starting point for community engagement, having experience of working with and supporting initiatives and involving users and members in debates about local needs, priorities and services. $^{3}$

For community organizations like 0xfamMonash that are engaging communities on the implementation of the NHI, it is important to 
take note of the following practical considerations:

- Effective community engagement includes coordinated implementation of the NHI policy initiative, a commitment to long-term investment of time and resources in the communities as the NHI will be implemented over a 14 year period, an openness to organizational and cultural change, a willingness to share power with NGOs and other key stakeholders in the communities you operate in and the development of mutual trust and respect with NGOs, communities and their leaders.

The infrastructure required for effective community engagement includes appropriate training and development of facilitators of community workshops, formal mechanisms to endorse partnership working and support for effective implementation of area-based initiatives. Some approaches that can be used to encourage communities to become involved in the understanding and implementation of the $\mathrm{NHI}$ include: i) involving community members as agents of change; ii) running community workshops; iii) drawing on the skills and experience of individuals and groups previously involved in HIV/AIDS and other health activities. Finally, there is a discussion of how better evaluation can be developed to increase understanding of how community engagement and the different approaches impact on health and social outcomes. Anthony Morgan, the Associate Director at National Institute for Health and Clinical Excellence (NICE) responsible for overseeing the guidance points out:

There's a very long journey from first engagement with a community to being able to evaluate health outcomes. Because of political constraints, funding for community engagement work tends to be for less than three years. This makes proper long-term evaluation more difficult. One of the lessons we learned from producing the guidance was that there is an important role for Government in commissioning large-scale pieces of research on the impact of community engagements. It should not be left to small community-based projects alone to carry out evaluative research. ${ }^{3}$

\section{Community engagement in practice}

A variety of approaches will be used to engage communities in the implementation of the NHI through the Oxfam-Monash NHI Accountability Project. These include the use of: i) local strategic partnerships (LSPs); ii) community workshops; and iii) the use of peer facilitators.

\section{Local strategic partnerships}

LSPs bring together organizations and agencies from the public, private, community and voluntary sectors within a local authority area. The aim of these non-statutory partner- ships is to improve joint working. ${ }^{3}$ The strategic partners in this project include Monash South Africa School of Health Sciences, Oxfam Australia project in South Africa, three nongovernmental organizations in the Eastern Cape, Limpopo and KwaZulu-Natal.

\section{Community workshops}

Community workshops are a commonly used technique for raising consumer awareness of a health topic or issue, facilitating the learning of new information and skills and encouraging behavior change. Traditional approaches to health education emphasize providing people with the facts about a particular health topic assuming that they will then adopt appropriate attitudes and behavior. Another approach involves the use of marketing techniques in which consumers are bombarded with information through mass media and elsewhere. More recently there has been an appreciation of the value of incorporating adult learning principles and of including consumers as active participants in the education process.

The community workshops take a health promotion approach with the aims of: i) strengthening community action in implementing the NHI or empowering communities; ii) developing personal skills, providing education and information; iii) creating a supportive environment (for the implementation of the NHI); iv) reorienting health services (to accommodate the new system); and v) helping Government to build a new public health policy. ${ }^{13}$

\section{Peer facilitators}

Peer leaders and educators will be selected from the local strategic partners and will be trained on how to provide information on the $\mathrm{NHI}$ and to facilitate discussion and input. They are peers as they work with people of the same age, background, culture or social status. They understand the language, culture, norms and values in the community and have previous experience working with the community.

\section{Conclusions}

There is little doubt that community engagement as an approach to improving health and health services and as a form of local accountability is here to stay. The forthcoming NHI initiative is a momentous and long-term structural change in South Africa's health system, which could take the practice of community engagement in health further into the mainstream.

During the launch of the policy document on the NHI in August, the Minister of Health, emphasized the importance of patients and the public, as well as clinicians, being involved from the beginning in the implementation of the NHI and has given a commitment that local people will be involved in any changes to the health services. Community organizations with experience in community engagement need to raise their hands now to get communities engaged in the understanding of the NHI and in making their voice heard.

The community engagement sessions that were conducted by Black Sash and Monash/Oxfam project in 2012 on the NHI helped achieve the Government's aim to devolve power to communities and create a more patient-focused and community-oriented NHI.

\section{References}

1. Communities and Local Government (CLG). An action plan for community empowerment: building on success. London: The Stationery Office; 2007. Available from: http://webarchive.nationalarchives.gov.uk/20120919132719/http://w ww.communities.gov.uk/documents/communities/pdf/actionplan Accessed: 25 April 2013.

2. Gregory J, Hartz-Karp J, Watson R. Using deliberative techniques to engage the community in policy development. Austr $\mathrm{N}$ Zeal Health Policy 2008;5:16.

3. Campbell F, Hughes L, Gilling T. Reaching out: community engagement and health. Londin: Improvement and Development Agency; 2008. Available from http://www. idea.gov.uk/idk/aio/8681034 Accessed: 25 April 2013.

4. Heginbotham C. European Union Green Paper. Improving the mental health of the population: towards a strategy on mental health for the European Union. A response from the Institute for Philosophy, Diversity and Mental Health within the Centre for Ethnicity and Health at the University of Central Lancashire. Preston: Centre for Ethnicity and Health, University of Central Lancashire; 2006. Available from: http://ec.europa.eu/health/archive/ph_dete rminants/life_style/mental/green_paper/m ental_gp_co118.pdf. Accessed: 25 April 2013.

5. Kahssay HM, Oakley PWHO. Community involvement in health development: A review of the concept and practice. Geneva: World Health Organization; 1999.

6. Coulter A. Engaging communities for health improvement. A scoping study for the Health Foundation. London: The Health Foundation; 2010. Available from: http://www.h org.uk/public/cms/75/76/313/597/Engaging 
\%20communities\%20for\%20health\%20im provement.pdf?realName $=78815 \mathrm{U}$.pdf Accessed: 25 April 2013.

7. Local Government Association, Health Commission. Who's accountable for health? Final report, 2008. London: LGA Publications; 2008. Available from: http://www.local.gov.uk/publications Accessed: 25 April 2013.

8. Paxman J. 'Making Scrutiny Work'. Speech to the Centre for Public Scrutiny CfPS First Annual Conference, June 2003. London: Queen Elizabeth II Conference Centre; 2003.
9. CfPS (Centre for Public Scrutiny). Out of control? The case for better health. In: The good scrutiny guide: a pocket guide for public scruitineers. London: CfPS; 2004.

10. Department of Health. Saving lives, our healthier nation, 1999. Report presented, to the British Parliament by the Secretary, of State for Health.

11. Popay J. Community engagement for health improvement: questions of definition, outcomes and evaluation. In: Morgan A, Barker R, Davies M, Ziglio E, eds. Health assets in a global context: theory, methods, action. New York: Springer; 2010. pp 183-197.
12. Harrison A, Montgomery E, Lurie M, et al. Barriers to implementing South Africa's Termination of Pregnancy Act in rural Kwazulu-Natal. Health Policy Politics 200;15:424-31.

13. Consumers' Health Forum of Australia. A guide for community organisations running health workshops with consumers; May 2003. Manuka, ACT: Consumers' Health Forum of Australia; 2003. Available from: https://www.chf.org.au/pdfs/rep/repguide-running-health-workshops.pdf Accessed: 25 April 2013. 